\title{
AN ANTISERUM AGAINST THE PC12 CELL LINE DEFINES CELL SURFACE ANTIGENS SPECIFIC FOR NEURONS AND SCHWANN CELLS $^{1}$
}

\author{
WILLIAM B. STALLCUP, ${ }^{2}$ LESLIE S. ARNER, AND JOEL M. LEVINE
}

Neurobiology Laboratory, The Salk Institute, San Diego, California 92138

\begin{abstract}
Antibodies raised in rabbits and in guinea pigs against nerve growth factor-treated PC12 cells were absorbed exhaustively with three non-neuronal cell lines. In immunofluorescent staining experiments, these absorbed sera, designated anti-PC12, labeled specifically several different types of cultured neurons, including cerebral, cerebellar, spinal, dorsal root, and superior cervical neurons. Non-neuronal cells in these cultures, such as astrocytes, oligodendrocytes, and fibroblasts, were not labeled. However, neural crest-derived adrenal chromaffin cells and Schwann cells were stained by anti-PC12. Further absorption with adrenal tissue rendered anti-PC12 specific for neurons and Schwann cells, while still further absorption with Schwann cells yielded an antiserum that was reactive only with dorsal root and superior cervical neurons. Absorption of anti-PC12 with adult brain resulted in the loss of activity against all cells except PC12 cells.

These absorption experiments suggested that anti-PC12 recognized at least four distinct cell surface components. Some anti-PC12-reactive components were identified by using the anti-PC12 serum to prepare immune precipitates from detergent extracts of ${ }^{125} \mathrm{I}$-labeled cells. The immune precipitates were analyzed by polyacrylamide gel electrophoresis. Anti-PC12 precipitated two components with apparent molecular weights of 190,000 and 140,000 that were common to Schwann cells, chromaffin cells, and all types of neurons. Smaller quantities of these two components could also be precipitated from cerebellar glial cells. In addition, anti-PC12 precipitated a glycoprotein of greater than 200,000 daltons from the cultured neurons, the neuronal cell lines, and the Schwann cells, but not from chromaffin cells or from cerebellar glia. Each neuronal cell type expressed a characteristic form of this large glycoprotcin, as judged by electrophoretic mobility. For example, the molecules found on four cell lines, $\mathrm{PC} 12, \mathrm{~B} 35, \mathrm{~N} 18$, and $\beta \mathrm{HC}$, had apparent molecular weights of $235,000,225,000,220,000$, and 215,000 , respectively. The 235,000 -dalton glycoprotein from PC12 cells is likely to be identical to the NILE glycoprotein described by McGuire et al. (McGuire, J., L. Greene, and A. Furano (1978) Cell 15: 357-365), while the 220,000-dalton component from N18 cells is probably similar to that described by Akeson and Hsu (Akeson, R., and W. Hsu (1978) Exp. Cell Res. 115: 367-377). Adrenal-absorbed anti-PC12 did not precipitate the 190,000- and 140,000-dalton components from any of the cell types but continued to precipitate the 215,000 - to 235,000 -dalton glycoproteins from the neurons and Schwann cells. These high molecular weight glycoproteins thus appear to be cell surface markers for neurons and Schwann cells.
\end{abstract}

The PC12 cell line (Greene and Tischler, 1976) shares many properties with sympathetic neurons and has thus provided an extremely useful model system for studying several types of neuronal mechanisms, including the function of neuronal acetylcholine receptors (Patrick and

\footnotetext{
' This work was supported by a Muscular Dystrophy Association research grant, by National Institutes of Health Grant NS 16112 to W. B. S., and by a Muscular Dystrophy Association postdoctoral fellowship to J. M. L. We thank Dr. David Schubert and Dr. Simon Halegoua for their helpful comments concerning these experiments.

${ }^{2}$ To whom correspondence should be addressed at Neurobiology Laboratory, The Salk Institute, P.O. Box 85800, San Diego, CA 92138.
}

Stallcup, 1977a, b; Stallcup and Patrick, 1980; Dichter et al., 1977), $\mathrm{Na}^{+}$channels (Stallcup, 1979; Dichter et al., 1977), $\mathrm{Ca}^{2+}$ channels (Stallcup, 1979; Ritchie, 1979), $\mathrm{K}^{+}$ channels (Arner and Stallcup, 1981), the synthesis and secretion of acetylcholine and catecholamines (Ritchie, 1979; Schubert et al., 1977; Greene and Rein, 1977), and the response to nerve growth factor (McGuire et al., 1978; Schubert et al., 1978). In light of the many similarities between PC12 cells and neurons, it seems likely that antisera raised against PC12 cells might define cell surface antigens specific to neurons. Lee et al. $(1977,1981)$ have shown that antisera raised against PC12 cells and absorbed with liver, kidney, spleen, and thymus do con- 
tain components that react with brain, sympathetic ganglia, and adrenal medulla, as well as with PC12 cells themselves. The specificity of the antisera for these tissues was evaluated by using tissue homogenates to perform both absorption and microcomplement fixation assays. Thus it was not possible to identify the actual cell types which bound antibody. In order to study the specificity of anti-PC12 sera at the cellular level, we have prepared antisera against NGF-treated $\mathrm{PC} 12$ cells and, after several types of absorptions, examined their immunofluorescent labeling patterns in primary cultures of brain, spinal cord, dorsal root ganglion, superior cervical ganglion, and adrenal medulla. Double labeling experiments were used to compare the staining obtained with anti-PC12 sera to the staining obtained with several other cell type-specific markers. These tests show that several different types of neurons and Schwann cells, but not CNS glial cells or fibroblasts, are labeled by the absorbed anti-PC12 antiserum.

Lee et al. (1981) also were able to show that their absorbed anti-PC12 sera recognized four major glycoprotein bands on the surface of both PC12 cells and sympathetic neurons. These glycoproteins had molecular weights of $230,000,180,000,160,000$, and 140,000 . The 230,000 -dalton glycoprotein was believed to be identical to the NILE glycoprotein described by McGuire et al. (1978). Absorption experiments using adrenal and brain tissue indicated that the 180,000 - and 140,000-dalton components were present in adrenals and that the $230,000-, 180,000$-, and 140,000-dalton components were present in brain. The types of brain cells which expressed these glycoproteins were not identified. With our rabbit anti-PC12 serum we have been able to show directly that it is possible to immunoprecipitate components of 190,000 and 140,000 daltons (probably similar to the $180,000-$ and 140,000-dalton components of Lee et al., 1981) from cultured CNS glial cells. Furthermore, in addition to the $190,000-$ and 140,000-dalton components, anti-PC12 immunoprecipitates a glycoprotein of greater than 200,000 daltons from all types of neurons examined (11 examples), including both central and peripheral neurons. Extending the work of Lee et al. (1981) on PC12 cells and sympathetic neurons and the work of Akeson and Hsu (1978) on mouse neuroblastoma cells, we have found that the exact molecular weight of this large glycoprotein depends on the species of neuron examined. In our hands these glycoproteins range in size from 235,000 daltons (PC12 cells) to slightly less than 215,000 daltons (spinal neurons). Thus, in the central nervous system, the 215,000 - to 235,000 -dalton glycoproteins are specific markers for neurons. In the periphery, Schwann cells, like sensory and sympathetic neurons, express a component with a molecular weight of about 225,000 in addition to the $190,000-$ and 140,000-dalton components. In contrast, cultured adrenal cells do not have a 215,000- to 235,000 -dalton component but do express the 190,000and 140,000-dalton components, in agreement with the absorption results reported by Lee et al. (1981).

\section{Materials and Methods}

Cell lines. The PC12 cell line (Greene and Tischler, 1976) and the PC-G2 cell line (Goodman and Herschman,
1978) were maintained in Dulbecco's modified Eagle's medium supplemented with $10 \%$ horse serum and $5 \%$ fetal calf serum. The B9, B92, B103, B35, B50, B90 (Schubert et al., 1974), $\beta$ HC, XKM (Bulloch et al., 1977), and L6 (Yaffe, 1968) cell lines were maintained in Dulbecco's modified Eagle's medium supplemented with $10 \%$ fetal calf serum.

Antisera. PC12 cells to be used for immunization were grown for 7 to 10 days in the presence of $60 \mathrm{ng} / \mathrm{ml}$ of NGF (2.5 S). Five immunizations with $10^{7}$ cells each were made at 2-week intervals. Cell suspensions were injected intravenously in the case of rabbits and intraperitoneally in the case of guinea pigs. Bleeds were taken 1 week after the third, fourth, and fifth immunizations and were pooled. These crude sera were processed as previously described (Stallcup and Cohn, 1976; Wilson et al., 1981). Briefly, gamma globulin fractions were prepared from both the rabbit and the guinea pig sera by making three successive precipitations with $40 \%$ ammonium sulfate. These gamma globulin preparations were diluted to a concentration of $5 \mathrm{mg} / \mathrm{ml}$ in PBS and spun at $100,000 \times$ $g$ for 10 min in a Beckman Airfuge before being absorbed three times with each of three cell lines: glial clones B9 and B92 and a pheochromocytoma clone, PC-G2. Thus a total of nine absorptions was made. Each absorption was carried out for $30 \mathrm{~min}$ at room temperature using 2 vol of antiserum to 1 vol of packed cells. These absorbed sera are referred to as rabbit and guinea pig anti-PC12 throughout the remainder of the paper.

Some absorptions also were made with other types of tissues and cells: (1) rat brain, (2) rat adrenals, (3) cultured rat sciatic nerve Schwann cells, (4) cultured rat cerebcllar cells, and (5) B35 cells. Brain and adrenals were taken from BDIX rats, homogenized in a Dounce homogenizer, and washed twice in HEPES-buffered Eagle's medium before being used for absorptions. The cultured cells were scraped from tissue culture dishes with rubber policemen and washed twice before being used for absorptions. The conditions for performing the absorptions were identical to those used for making the anti-PC12 serum itself. Absorption with a given cell or tissue type was always done three times.

Rabbit anti-PC12 also was absorbed with each of six glycosaminoglycans, heparin, heparan sulfate, hyaluronic acid, chondroitin sulfate $A$, chondroitin sulfate $B$, and chondroitin sulfate $\mathrm{C}$, as well as with a combination of all six (at concentrations of $10^{-3} \mathrm{M}$ based on glucuronic acid content). Diluted anti-PC12 was incubated with the glycosaminoglycans at room temperature for $1 \mathrm{hr}$ to allow any binding of the antibody to the glycosaminoglycans. These mixtures of anti-PC12 and glycosaminoglycans then were used to stain cerebellar cultures as described below. In these experiments, anti-PC12 was used at a 1:20 dilution, a threshold concentration, such that any diminution of titer as judged by fluorescence intensity would be noticeable.

Tetanus toxin and both horse and rabbit antitoxin were gifts from Dr. R. O. Thomson of Wellcome Laboratories. Rabbit anti-dopamine $\beta$-hydroxylase (antiDBH) was a gift from Dr. T. Joh. Mouse anti-RAN-1 antibody was provided by Dr. J. Brockes. Rabbit antiglial fibrillary acidic protein (anti-GFAP) was a gift of 
Dr. A. Bignami. Rabbit anti-galactocerebroside (antiGC), prepared according to the method of Raff et al. (1978), was the gift of Dr. R. Milner. Rabbit anti-human fibronectin was obtained from Collaborative Research Inc.

Goat antibodies to rabbit, horse, mouse, and guinea pig immunoglobulins (N. L. Cappel Laboratories Inc.) were conjugated to fluorescein isothiocyanate or tetramethylrhodamine isothiocyanate. These secondary antisera were tested as described (see Stallcup, 1981) to ensure that there was no undesired cross-reactivity with inappropriate immunoglobulin species (e.g., goat antirabbit immunoglobulin with horse immunoglobulin).

Primary cultures. All dissociated rat cell cultures were prepared from tissues of either BDIX or Sprague-Dawley rats. Cultures of 15-day embryonic brain and of 3-day postnatal cerebellum were prepared as described by Stallcup (1981), cultures of 12-day embryonic spinal cord (SC) were prepared according to the method of Ransom et al. (1977), cultures of 2-day postnatal dorsal root ganglia (DRG) were prepared according to the method of Fields et al. (1978), and cultures of 2-day postnatal superior cervical ganglia (SCG) were prepared according to the method of Hawrot and Patterson (1979). Cultures of adrenal medulla were prepared from 2-day postnatal and adult rats as described by Brandt et al. (1976) except that the cells were plated on polylysine-coated dishes to enhance adhesion. Cultures of sciatic nerve Schwann cells were prepared from 5-day postnatal rats and maintained according to the method of Brockes et al. (1979). Cerebellar cultures devoid of neurons were prepared by passaging cells from the original cultures at low density at least two times and allowing these cultures to grow to confluency. Since the non-neuronal cells, but not the neuronal cells, continued to divide, the cultures were soon overgrown by non-neuronal cells. Cultures of DRG and SCG neurons without Schwann cells were obtained by treating the cultures with $10^{-5} \mathrm{M}$ cytosine arabinoside for up to 1 week to kill the mitotically active Schwann cells and fibroblasts. Cultures of Xenopus embryonic (stage 24) spinal cord and myotomal muscle were prepared as described by Kidokoro et al. (1980).

Immunofluorescent labeling. The various labeling reagents were diluted into HEPES-buffered Eagle's medium containing $1 \%$ calf serum and were spun for $10 \mathrm{~min}$ in an Eppendorf centrifuge. Tetanus toxin was used at 5 to $10 \mu \mathrm{g} / \mathrm{ml}$. Each of the antisera was used at a 1:50 dilution with the exception of the anti-PC12 sera, which were used at 1:10 or 1:20, and the anti-DBH antibody, which was used at 1:200.

Interesting areas of the cultures were isolated in rings of silicon grease, washed with the HEPES medium, and incubated with 50 to $100 \mu \mathrm{l}$ of diluted primary antiserum for $30 \mathrm{~min}$ at room temperature. For double labeling, the cultures were treated with both antisera simultaneously (except in the case of anti-GFAP and anti-DBH; see below). The cultures were washed four times with HEPES medium and then exposed to the fluorochromelabeled second antibody or the appropriate mixture of two second antibodies for another $30 \mathrm{~min}$. After four more washings, the plates were air dried and fixed with cold $95 \%$ ethanol for $10 \mathrm{~min}$. When anti-GFAP or anti-
DBH was used for double labeling, cultures first were exposed to the other primary antibody and its fluorescent reagent, then fixed in ethanol and finally treated with anti-GFAP or anti-DBH and its fluorescent reagent.

Labeled areas of the plate were cut out with a hot razor blade and mounted with a coverslip in Tris-buffered glycerol, $\mathrm{pH}$ 8. Cells were examined with a Zeiss microscope equipped for phase optics and for epifluorescence. Photography was done with a Nikon $35-\mathrm{mm}$ camera using Kodak Tri-X/400 film. Exposures of $30 \mathrm{sec}$ to $2 \mathrm{~min}$ were used for the fluorescence photographs.

Cell surface radioiodination and identification of cell surface components. Cell lines and primary cultures were labeled with ${ }^{125} \mathrm{I}$ using the lactoperoxidase technique (Hubbard and Cohn, 1972). After washing, the cells were lysed in 1\% NP40 and the soluble extract was used for immunoprecipitation experiments. Usually, 50 to $100 \mu \mathrm{l}$ of extract were incubated at room temperature for $1 \mathrm{hr}$ with $10 \mu \mathrm{l}$ of the rabbit anti-PC12. Fifty microliters of goat anti-rabbit immunoglobulin then were added to effect immune precipitation. These precipitates were washed three times with PBS, dissolved by boiling in gel electrophoresis sample buffer containing 3\% SDS and 5\% mercaptoethanol, and electrophoresed on 5\% polyacrylamide slab gels (Laemmli, 1970). Gels were dried under reduced pressure and autoradiographed on Kodak XAR5 film using Cronex intensifying screens (DuPont).

\section{Results}

Immunofluorescent staining with anti-PC12. The gamma globulin fraction of the rabbit anti-PC12 serum was absorbed with two glial cell lines, B9 and B92, and with another pheochromocytoma clone, PC-G2, which does not extend neurites in response to NGF and which in our hands shows no evidence of having voltage-dependent $\mathrm{Na}^{+}$channels or acetylcholine receptors (W. Stallcup, unpublished observations). This absorbed antibody still reacted with $\mathrm{PC} 12$ cells, both undifferentiated (Fig. 1, $A$ and $B$ ) and grown in the presence of NGF (Fig. $1, C$ and $D$ ). In addition, the absorbed antibody stained specifically what appeared to be nerve fibers in cultures of rat cerebellum (Fig. 1, $E$ and $F$ ). By comparison, the unabsorbed serum stained not only nerve fibers but also many of the flat cells in the monolayer covering the surface of the tissue culture dish (Fig. 1, $G$ and $H$ ). 'This unabsorbed serum will not be mentioned again, and we will henceforth use the name anti-PC12 to refer specifically to the antiserum absorbed with B9, B92, and PCG2 cells.

To confirm the neuronal specificity of the rabbit antiPC12 serum, we double labeled cultures with anti-PC12 and with tetanus toxin, which has been shown to be a specific label for many types of neuronal cells in culture (Mirsky el al., 1978; Fields et al., 1978). Although minor differences in the labeling of individual neurites occasionally could be found, these double labeling studies showed clearly that rabbit anti-PC12 and tetanus toxin reacted with the same cells in cultures of rat cerebrum (Fig. 2, $A$ to $C$ ) and rat cerebellum (not shown).

To establish that anti-PC12 did not stain other types of cells, such as glia and fibroblasts, it was necessary to perform double labeling experiments with anti-PC12 and 



Figure 1. Immunofluorescent staining with anti-PC12. Field 1, Undifferentiated PC12 cells stained with rabbit anti-PC12 and R-GaRIg. ${ }^{3}$ Magnification $\times 500$. A, Phase; B, anti-PC12. Field 2, NGF-treated PC12 cells stained with rabbit anti-PC12 and R-GaRIg. Magnification $\times 800$. C, Phase; D, anti-PC12. Field 3, Postnatal day 3 cerebellar culture stained with anti-PC12 and R-GaRIg. Magnification $\times 800$. E, Phase; $F$, anti-PC12. Field 4, Postnatal day 3 cerebellar culture stained with unabsorbed rabbit anti-PC12 and R-GaRIg. Magnification $\times 400$. $G$, Phase; $H$, anti-PC12.

the cell-specific markers anti-GFAP for astrocytes (Bignami et al., 1972), anti-GC for oligodendrocytes (Raff et al., 1978), and anti-fibronectin for fibroblasts (Schachner et al., 1978). Since these three other antisera were all prepared in rabbits, we used the guinea pig anti-PC12 (absorbed with B9, B92, and PC-G2 cells in exactly the same way as rabbit anti-PC12) for these experiments. Like rabbit anti-PC12, guinea pig anti-PC12 labeled the same cells as did tetanus toxin in cultures of rat cerebellum (Fig. 2, $D$ to $F$ ) and rat cerebrum (not shown). Furthermore, the guinea pig anti-PC12 did not label GFAP-positive astrocytes, GC-positive oligodendrocytes,

\footnotetext{
${ }^{3}$ The abbreviations used in the figure legends are: F-GaHIg, fluorescein-labeled goat antibody against horse immunoglobulin; F-GaRIg, fluorescein-labeled goat antibody against rabbit immunoglobulin; $\mathrm{Ha}$ tetanus toxin, horse anti-tetanus toxin; Ra tetanus toxin, rabbit antitetanus toxin; R-GaGPIg, rhodamine-labeled goat antibody against guinea pig immunoglobulin; R-GaRIg, rhodamine-labeled goat antibody against rabbit immunoglobulin.
}

or fibronectin-positive fibroblasts (Fig. 3). Thus, in these immunofluorescence experiments, the anti-PC12 sera appear to stain specifically the neurons in primary cultures of rat brain. One feature of anti-PC12 staining that we noticed regularly in these primary brain cultures, especially those of cerebellum, was the relative absence of labeling on the neuronal cell bodies compared to the neurites. Figures $1 F, 2 E, 3 B$, and $3 H$ are examples of this selective neurite labeling. (See Lee et al., 1980, for discussion of a related observation.)

Since these brain cultures almost certainly contained more than a single type of neuron, it seemed likely that the antigen (or antigens) recognized by anti-PC12 must be shared by a variety of different neurons. In an attempt to determine if this antigen(s) was also found on neurons outside the brain, we stained several other preparations with anti-PC12. Anti-PC12 labeled tetanus toxin-positive spinal cord neurons, DRG neurons, and SCG neurons. In addition, anti-PC12 labeled DBH-positive adrenal chromaffin cells and RAN-1-positive Schwann cells (Brockes 
et al., 1977), both of which, like DRG and SCG neurons, are derived from the neural crest. Unlike the neurons from the brain, spinal cord, and peripheral ganglia, the Schwann cells and chromaffin cells were not labeled with tetanus toxin.

Further absorption of anti-PC12. Since anti-PC12 recognized several different types of cells, we tried further absorption experiments with the antiserum to see if subclasses of reactive cells could be defined. It is important to recognize the limitations of these absorption experiments. For example, it is very difficult, if not impossible, to determine by absorption whether a given cell type expresses absolutely none of a particular antigen or whether it merely expresses a very tiny amount of the antigen. This problem is magnified in the case of heterogeneous tissues such as brain or adrenal gland in which there are undetermined numbers of different cell types. In the brain, for example, although a particular antigen might be carried at a reasonable density on a particular type of nerve cell, if this population of cells makes up a very small fraction of the total cell population, we may very well fail to detect the presence of the antigen. One may argue that additional absorptions would reveal the presence of the antigen, but what is a reasonable number of absorptions? Based on past experience, we adopted the following method of procedure for both the immunofluorescence and immunoprecipitation experiments done with our absorbed antibodies. We made one absorption (according to the protocol outlined under "Materials and Methods") and tested the antiserum to see what changes in reactivity had occurred. We tried to concentrate on major changes, since subtle changes could be caused by nonspecific absorption and dilution. We then did two more absorptions (for a total of three) and tested the antiserum for any further changes in reactivity. If the results were essentially unchanged by the two additional absorptions, we felt relatively confident in assuming that a steady state level of reactivity had been reached. Some of the data to be discussed below show that three absorptions are in fact capable of detecting a fairly low level of antigen.

Our absorption experiments are summarized in Table I. Absorption of the anti-PC12 serum with PC12 cells themselves removed staining activity against all types of
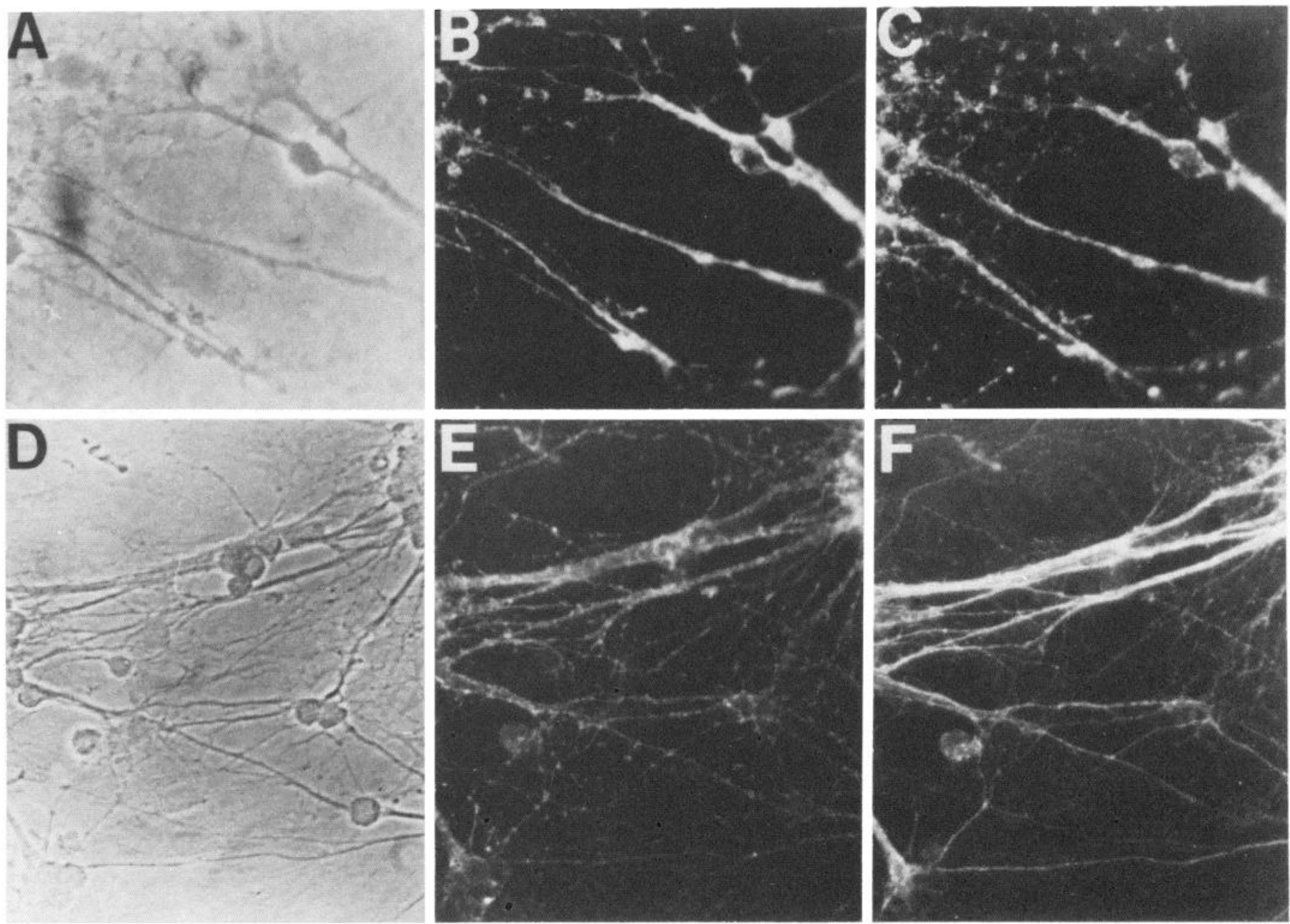

Figure 2. Anti-PC12 stains tetanus toxin-positive neurons in brain cultures. Field 1, Culture of embryonic day 16 brain double stained with rabbit anti-PC12 and R-GaRIg and with tetanus toxin, Ha tetanus toxin, and F-GaHIg. Magnification $\times 700$. $A$, Phase; $B$, anti-PC12; $C$, tetanus toxin. Field 2 . Culture of postnatal day 3 cerebellum double stained with guinea pig anti-PC12 and R-GaGPIg and with tetanus toxin, Ra tetanus toxin, and F-GaRIg. Magnification $\times 700 . D$, Phase; $E$, anti-PC12; F, tetanus toxin. 

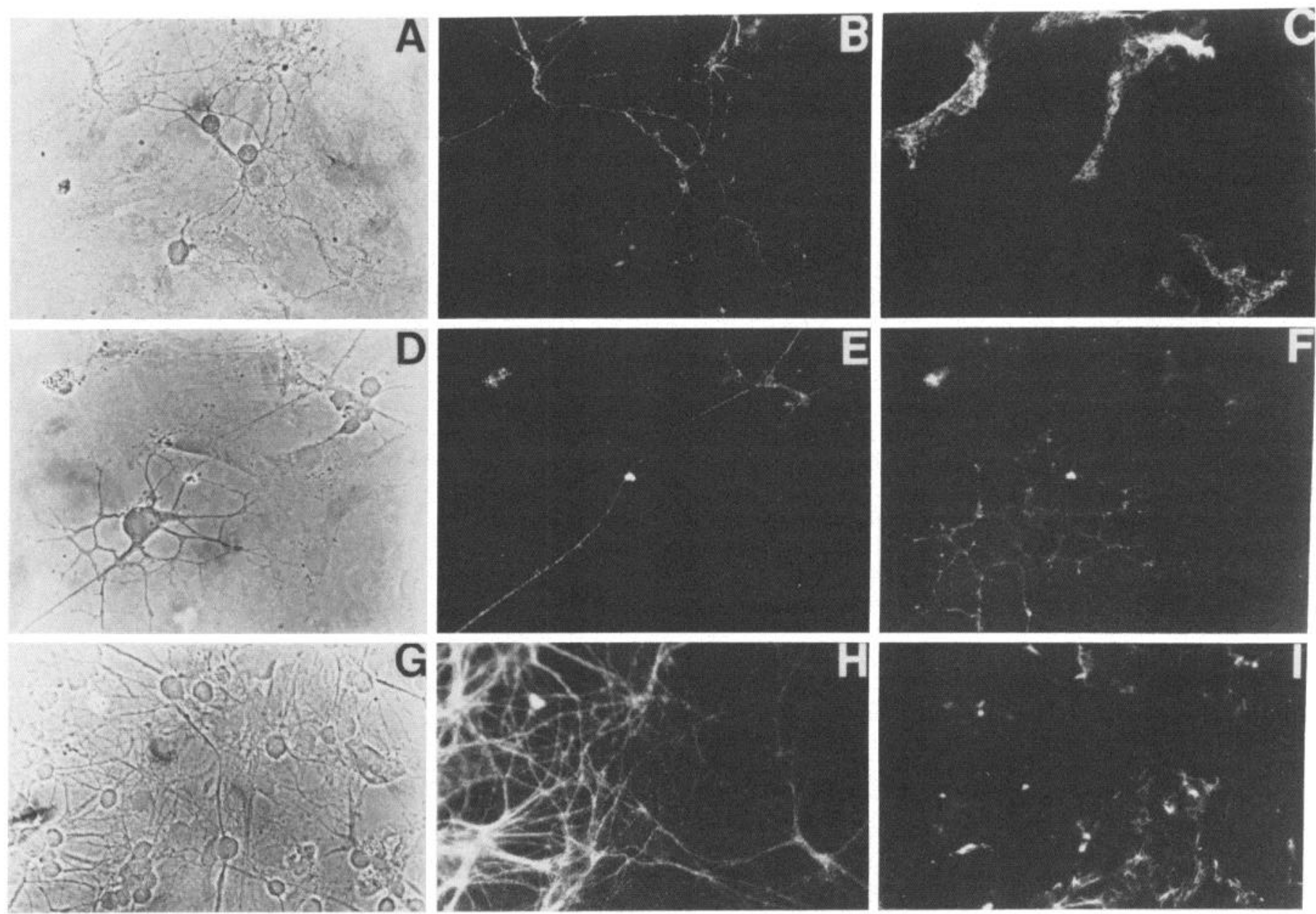

Figure 3. Anti-PC12 does not stain non-neuronal cells in postnatal day 3 cerebellar cultures. Field 1, Double-staining with guinea pig anti-PC12 and R-GaGPIg and with rabbit anti-GFAP and F-GaRIg. Magnification $\times 600$. $A$, Phase; $B$, anti-PC12; $C$, anti-GFAP. Field 2, Double-staining with guinea pig anti-PC12 and R-GaGPIg and with rabbit anti-GC and F-GaRIg. Magnification $\times 600$. $D$, Phase; $E$, anti-PC12; $F$, anti-GC. Field 3, Double staining with guinea pig anti-PC12 and R-GaGPIg and with rabbit anti-fibronectin and F-GaRIg. Magnification $\times 600$. $G$, Phase; $H$, anti-PC12; $I$, anti-fibronectin.

TABLE I

Effect of absorption with various cell types on immunofluorescent staining with anti-PC12

\begin{tabular}{|c|c|c|c|c|c|c|c|c|c|c|}
\hline \multirow[b]{2}{*}{ Cell Type } & \multirow[b]{2}{*}{$\mathrm{PC}^{a}$} & \multirow[b]{2}{*}{$\begin{array}{c}\mathrm{PC} \text { abs } \\
\mathrm{PC} 12\end{array}$} & \multirow[b]{2}{*}{$\begin{array}{l}\text { PC abs } \\
\text { CBL-G }\end{array}$} & \multirow[b]{2}{*}{$\mathrm{PC}$ abs Adr } & \multirow[b]{2}{*}{$\begin{array}{c}\text { PC abs Adr, } \\
\text { Sch }\end{array}$} & \multirow[b]{2}{*}{$\begin{array}{c}\text { PC abs Adr, } \\
\text { B35 }\end{array}$} & \multirow[b]{2}{*}{$\begin{array}{c}\text { PC abs Adr, } \\
\text { CBL }\end{array}$} & \multirow[b]{2}{*}{$\begin{array}{l}\text { PC abs Adr, } \\
\text { CBL-G }\end{array}$} & \multicolumn{2}{|c|}{$\mathrm{PC}$ abs } \\
\hline & & & & & & & & & $\begin{array}{l}\text { Adult } \\
\text { Brain }\end{array}$ & $\begin{array}{l}\text { Fetal } \\
\text { Brain }\end{array}$ \\
\hline $\mathrm{PC} 12$ & $++^{b}$ & $-^{c}$ & ++ & ++ & $+^{d}$ & + & + & ++ & + & + \\
\hline Cerebellar neurons & ++ & - & ++ & ++ & - & - & - & ++ & - & - \\
\hline Spinal neurons & ++ & - & ++ & ++ & - & - & - & ++ & - & - \\
\hline DRG neurons & ++ & - & ++ & ++ & + & + & + & ++ & - & + \\
\hline Chromaffin cells & ++ & - & - & - & - & - & - & - & - & - \\
\hline
\end{tabular}

${ }^{a}$ PC, anti-PC12; abs, absorbed; Adr, adrenals; Sch, Schwann cells; CBL, cerebellar cultures; CBL-G, cerebellar glial cultures without neurons.

${ }^{b}++$, strong staining.

$c-$, no staining.

${ }^{d}+$, moderate staining.

cells tested, including PC12. On the other hand, antiPC12 absorbed with adult rat adrenal tissue continued to stain all of the neuronal cell types and the Schwann cells and failed to stain only the adrenal cultures (Figs.
4 and 5). The absence of labeling on adrenal cells was found in the case of cultures prepared from both adult and newborn rats and was independent of the age of the cultures over a period of 2 to 10 days in vitro. This 
adrenal-absorbed antiserum was further absorbed in several ways. When sciatic nerve Schwann cells were used for the absorption, the antiserum continued to stain PC12 cells and DRG and SCG neurons but no other cell type (Fig. 6). Likewise, absorption of adrenal-absorbed antiPC12 with the B35 neuronal line or with cerebellar cultures removed all staining activity except that against PC12 cells and DRG and SCG neurons (not shown). In contrast, absorption with cerebellar cultures devoid of neurons had no effect on the adrenal-absorbed anti-PC12, showing that neurons are required to absorbed the reactivity against CNS neurons and Schwann cells.

Absorption of anti-PC12 with 18-day embryonic rat brain yielded an antiserum that was still able to stain PC12 cells and both DRG and SCG neurons. This antiserum was therefore equivalent to that obtained by absorption of the adrenal-absorbed anti-PC12 with Schwann cells, B35 cells, or cerebellar cultures. In contrast, absorption of anti-PC12 with 2-month-old rat brain removed staining activity against all cell types except PC12 cells (see Figs. 4 and 5). Although it is possible that this residual staining of $\mathrm{PC} 12$ cells reflects the presence of a strain-specific or histocompatibility antigen (PC12 cells are derived from New England Deaconess Hospital (NEDH) rats, whereas we have used BDIX rats for our studies), it is worth noting that Lee et al. (1977) also found PC12-specific antigens after absorption of their antisera with NEDH brain and adrenals.

These absorption experiments show that anti-PC12 recognizes at least four distinct classes of antigens. $(a)$ One of these is present on PC12 cells, in adrenal tissue, in both fetal and adult brain, and on cultured cerebellar glial cells. The absorption data do not allow us to decide whether this antigen is also present on other neuronal cell lines, on Schwann cells, or on DRG and SCG neurons, since no absorptions with these cell types were performed on the anti-PC12 serum itself. (b) A second antigen is present on PC12 cells, in both fetal and adult brain, on B35 cells, on cerebellar neurons, and on Schwann cells. Adrenal chromaffin cells and cerebellar glial cells do not express this antigen. Once again, we cannot determine from the absorption data if this antigen is present on
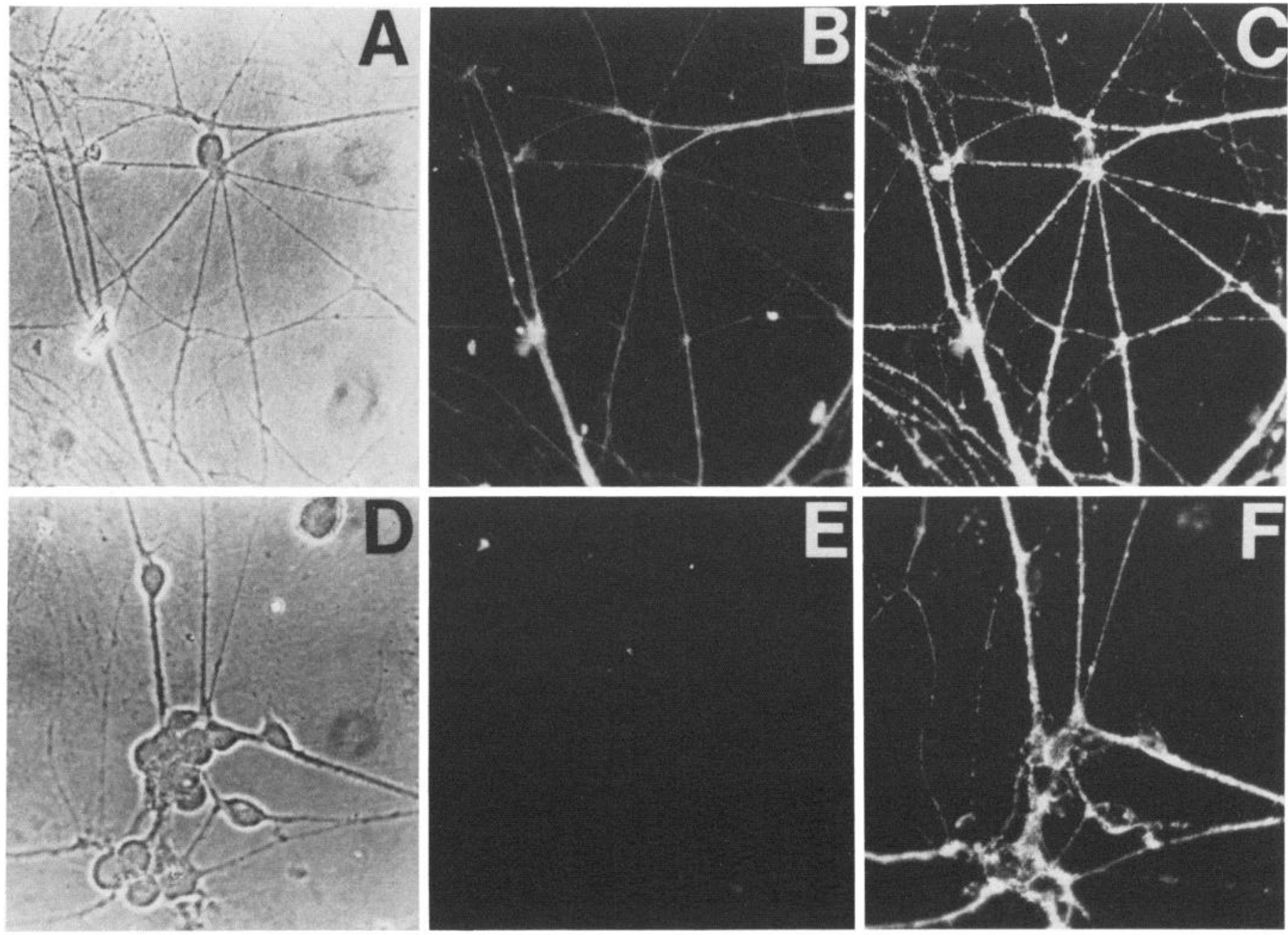

Figure 4. Postnatal day 3 cerebellar cultures double stained with tetanus toxin and with adrenal- and brain-absorbed antiPC12. Field 1, Double staining with adrenal-absorbed rabbit anti-PC12 and R-GaRIg and with tetanus toxin, Ha tetanus toxin, and F-GaHIg. Magnification $\times 700$. A, Phase; B, adrenal-absorbed anti-PC12; $C$, tetanus toxin. Field 2, Double staining with brain-absorbed rabbit anti-PC12 and R-GaRIg and with tetanus toxin, Ha tetanus toxin, and F-GaHIg. Magnification $\times 800$. $D$, Phase; $E$, brain-absorbed anti-PC12; $F$, tetanus toxin. 

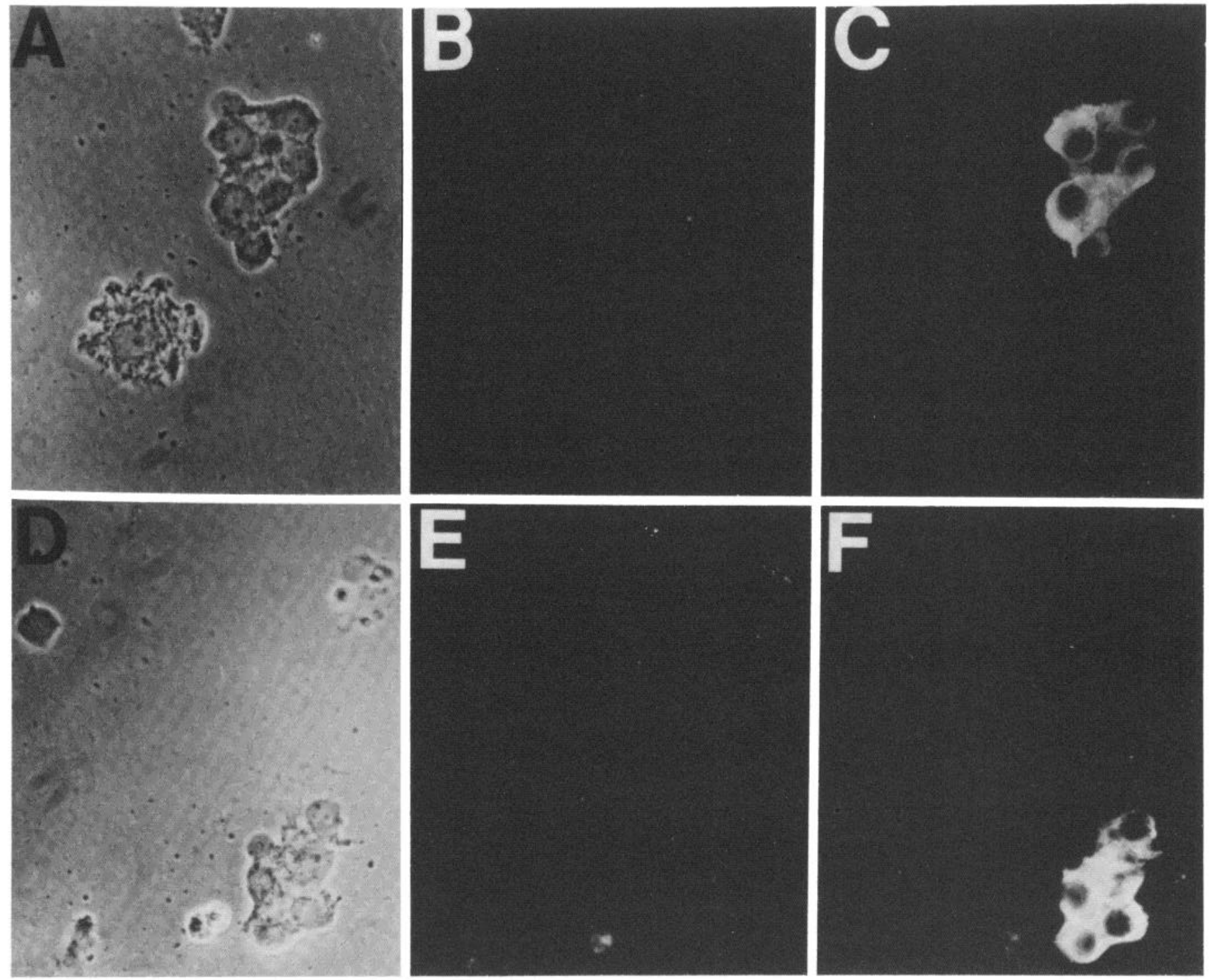

Figure 5. Cultures of adrenal medulla double stained with anti-DBH and with adrenal- and brain-absorbed anti-PC12. Field 1 , Double staining with adrenal-absorbed rabbit anti-PC12 and R-GaRIg and with anti-DBH and F-GaRIg. Magnification $\times 700$. $A$, Phase; $B$, adrenal-absorbed anti-PC12; $C$, anti-DBH. Field 2, Double-staining with brain-absorbed rabbit anti-PC12 and RGaRIg and with anti-DBH and F-GaRIg. Magnification $\times 700$. $D$, Phase; $E$, brain-absorbed anti-PC12; $F$, anti-DBH.

DRG or SCG neurons since no absorptions were done with these cells. (c) A third antigen is present on $\mathrm{PC} 12$ cells, on DRG and SCG neurons, and in adult brain. No other cell types express this antigen. $(d)$ A fourth antigen is present only on PC12 cells. Although it would have been possible for us to make the listings under antigen classes $a$ and $b$ more complete by performing more absorptions with other cell types (such as DRG or SCG neurons, for example), we decided instead to concentrate our efforts on achieving a more direct identification of antigenic cell surface molecules which might correspond to the four antigenic classes proposed above on the basis of the existing absorption data.

Molecular characterization of components recognized by anti-PC12. An important question is the nature of the components on the neuronal cell surface that are recognized by anti-PC12. Clearly, there are numerous candi- dates for these components, but we considered three types of molecules. First, because anti-PC12 and tetanus toxin bind to the same cells, anti-PC12 might bind to the same gangliosides (GD1b and GT1) (Dimpfel et al., 1977) that are recognized by tetanus toxin. This alternative was ruled out, however, since Xenopus spinal cord neurons were stained with tetanus toxin but not with antiPC12. Apparently, the component recognized by antiPC12 is not conserved across such a wide species difference. Conversely, we found two types of cells, Schwann cells and a mouse cell line $\beta \mathrm{HC}$, which did not bind tetanus toxin but which were labeled by anti-PC12. The component recognized on Schwann cells and $\beta \mathrm{HC}$ cells was found on brain cells but not adrenal cells, since absorption with adult rat brain but not adrenals removed the ability of anti-PC12 to stain Schwann cells and $\beta \mathrm{HC}$ cells. These data show that anti-PC12 does not recognize 
the gangliosides responsible for tetanus toxin binding. Obviously, there are a number of other gangliosides for which this same statement cannot be made.

A second possibility was that anti-PC12 recognized the glycosaminoglycans present on the neuronal cell surface. As described under "Materials and Methods," we tested six glycosaminoglycans to see if they were able to interfere with immunofluorescent labeling of cultured cerebellar neurons by anti-PC12. Heparin, heparan sulfate, hyaluronic acid, chondroitin sulfate A, chondroitin sulfate $B$, chondroitin sulfate $C$, and a mixture of all six glycosaminoglycans were tried. No loss of labeling intensity of the cerebellar neurons was apparent in any case, suggesting an inability of anti-PC12 to recognize determinants found on the glycosaminoglycans.

A third possibility is that anti-PC12 binds to proteins or glycoproteins on the neuronal cell surface. To investigate this possibility, we radiolabeled the surface of PC12 cells with ${ }^{125} \mathrm{I}$ using the lactoperoxidase technique.
NP40 extracts of the iodinated cells were used for immunoprecipitation with the anti-PC12 antibody, and the precipitates obtained were analyzed by SDS-polyacrylamide gel electrophoresis. Figure 7 shows that the major component precipitated from $\mathrm{PC} 12$ by anti-PC12 had an apparent molecular weight of 235,000 . This molecule was not one of the major components in the total PC12 extract and was enriched dramatically in the immune precipitate. Other components with molecular weights of $190,000,170,000$, and 140,000 also were precipitated by anti-PC12 but were not clearly visible without much longer autoradiographic exposures. All four of these components are likely to be glycoproteins since they also were seen in precipitates prepared from $\mathrm{PC} 12$ cells that were labeled biosynthetically with $\left[{ }^{14} \mathrm{C}\right]$ leucine and $\left[{ }^{35} \mathrm{~S}\right]$ methionine or with $\left[{ }^{14} \mathrm{C}\right]$ galactose (data not shown).

As expected from the separate nature of the anti-PC12 and tetanus toxin binding sites, none of the four antiPC12-precipitable glycoproteins were precipitated by
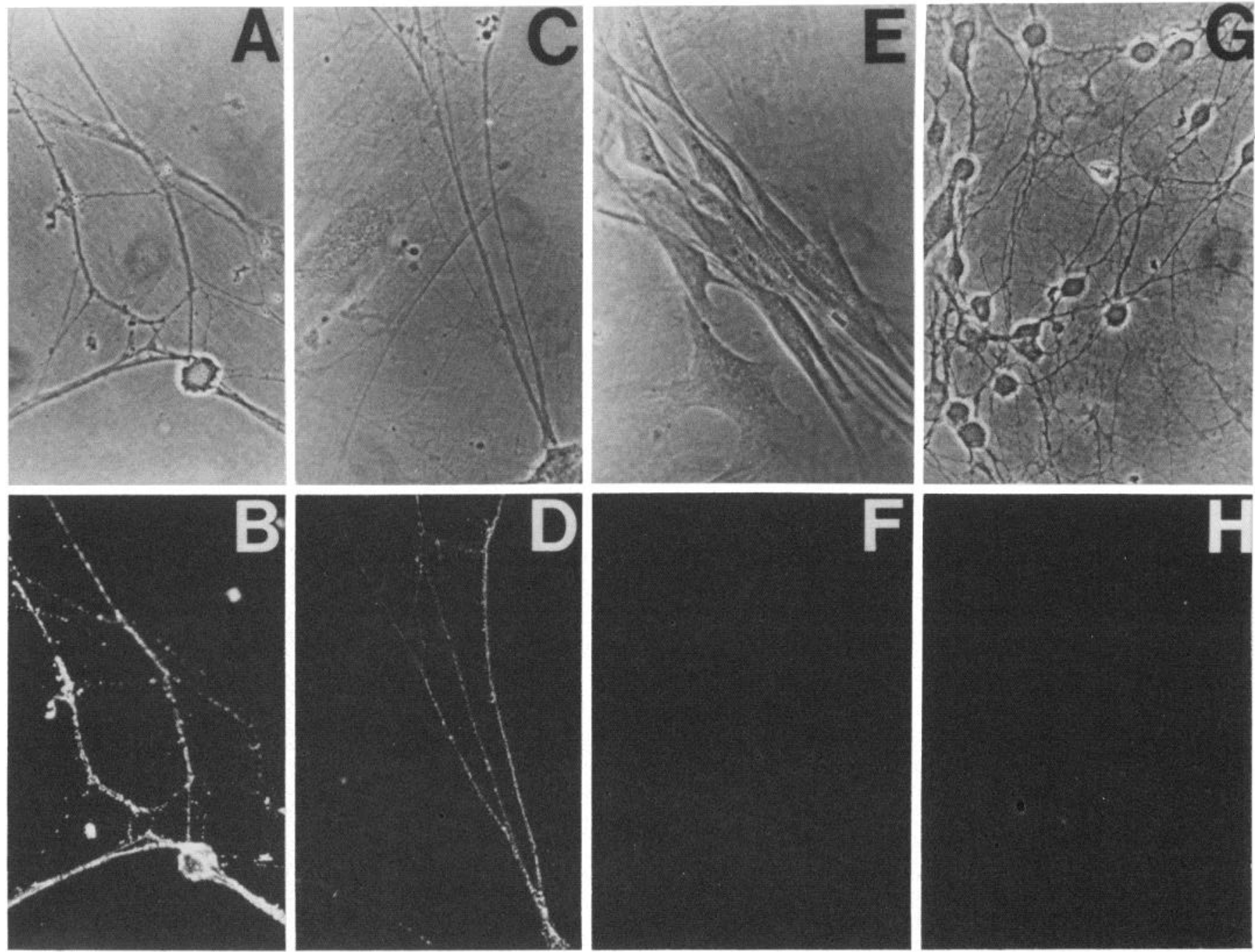

Figure 6. Staining of cultures with adrenal- and Schwann cell-absorbed anti-PC12 and R-GaRIg. Field 1, DRG culture. Magnification $\times 650$. A, Phase; $B$, adrenal and Schwann cell-absorbed anti-PC12. Field 2, SCG culture. Magnification $\times 500$. $C$, Phase; D, adrenal and Schwann cell-absorbed anti-PC12. Field 3, Sciatic nerve Schwann cell cultures. Magnification $\times 500$. E, Phase; $F$, adrenal- and Schwann cell-absorbed anti-PC12. Field 4, Postnatal day 3 cerebellar culture. Magnification $\times 600$. G, Phase; $H$, adrenal- and Schwann cell-absorbed anti-PC12. 
treatment of $\mathrm{PC} 12$ extracts with tetanus toxin, rabbit anti-tetanus toxin, and goat anti-rabbit gamma globulin. Likewise, rabbit anti-fibronectin and goat anti-rabbit gamma globulin failed to precipitate these molecules from PC12 extracts. On the other hand, anti-fibronectin, but not anti-PC12, precipitated a component of about 250,000 daltons from labeled extracts of L6 myoblasts, which are known to contain fibronectin. Anti-PC12 also failed to precipitate any labeled components from extracts of several iodinated glial cell lines (B9, B90, B92, C6) and from PC-G2 cells.

In contrast to these negative results, parallel iodination and precipitation experiments with other neuronal cell lines revealed labeled components in every case tested. For most neuronal cell lines the dominant component was one with an electrophoretic mobility similar but not identical to that of the 235,000-dalton PC12 component (Fig. 7). For example, anti-PC12 precipitated components with apparent molecular weights of about 225,000 and 220,000 (as well as some components of lower molecular weight) from B35, a rat CNS line (Schubert et al., 1974), and $\mathrm{C} 1300$ clone N18, a mouse neuroblastoma (Amano et al., 1972), respectively. The mouse cell line $\beta \mathrm{HC}$ (Bulloch et al., 1977), which has properties intermediate between neuronal and glial cells (Arner and Stallcup, 1981; Wilson et al., 1981), had a major cross-reactive component of about 215,000 daltons. Several other neuronal cell lines such as B103, B50, and XKM cl.1 (Schubert et al., 1974; Bulloch et al., 1977) also had dominant cross-reactive molecules in the 220,000 - to 230,000 -dalton range as well as minor components of lower molecular weight (not shown).

To test whether these glycoproteins were released into the medium from the cell surface (see Schubert, 1976), we performed an experiment in which iodinated PC12, B35, and N18 cells were not extracted with detergent but

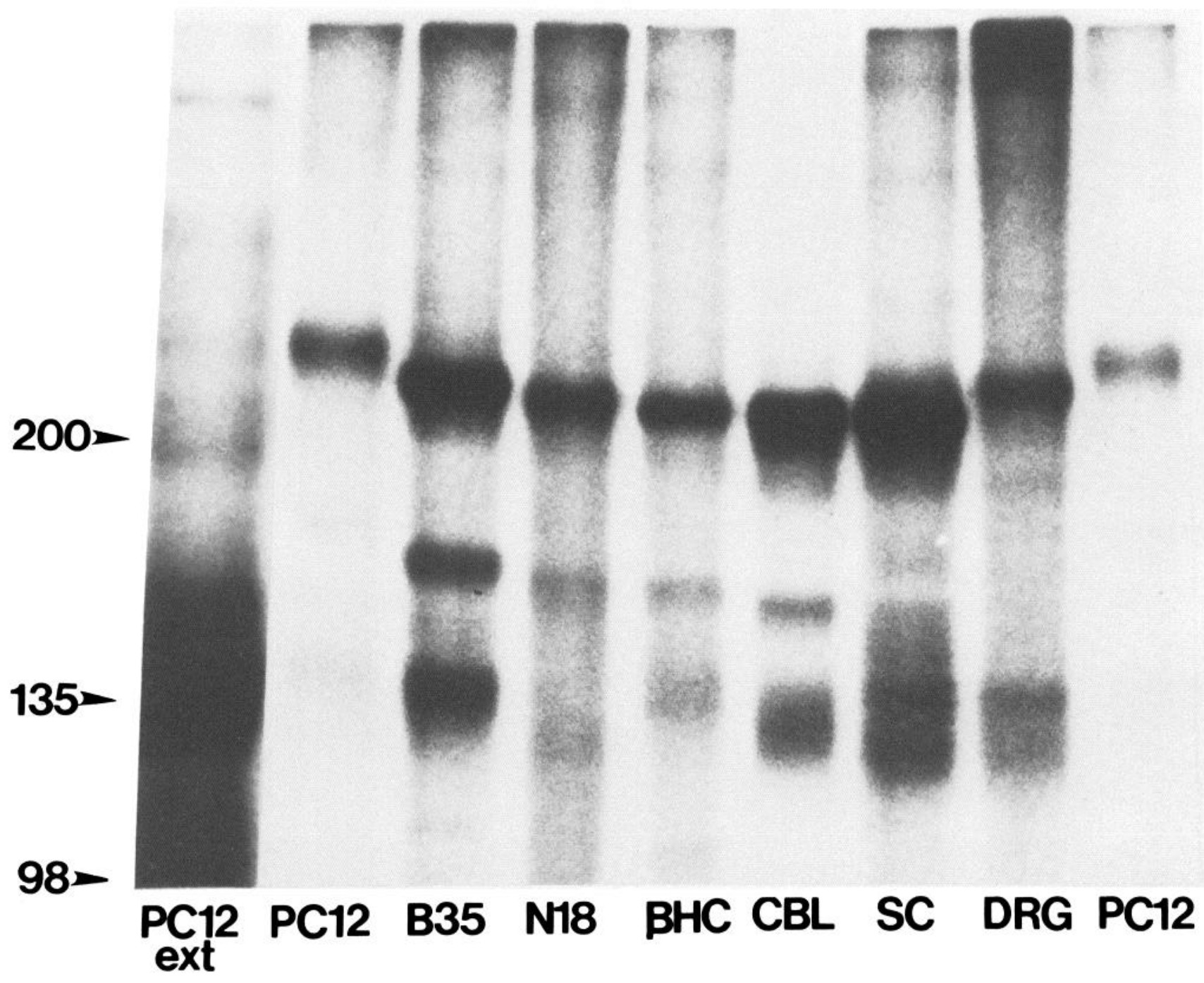

Figure 7. Identification of ${ }^{125} \mathrm{I}$-labeled membrane components precipitated by anti-PC12. This is an autoradiograph of a $5 \%$ polyacrylamide-SDS gel. Numbers on the left indicate the positions of standards with molecular weights of $200,000,135,000$, and 98,000 . The first lane shows the pattern produced by a sample of the total NP40 extract of ${ }^{125}$ I-labeled PC12 cells. All other lanes are anti-PC12 immune precipitates of the indicated cell types: $\mathrm{PC} 12, \mathrm{~B} 35, \mathrm{C} 1300 \mathrm{~N} 18, \beta \mathrm{HC}$, cerebellar culture $(C B L)$, spinal cord culture $(S C)$, and DRG culture (DRG). 
were incubated in serum-free Eagle's medium. After 5 to $6 \mathrm{hr}$ the cells were removed by centrifugation, and the supernatants were used for immune precipitations. In each of these three cases a high molecular weight band was precipitated that migrated slightly faster on polyacrylamide gels than the major high molecular weight band derived from a detergent extract of the same cell line (not shown). In each case the difference in electrophoretic mobility between the detergent-extracted and shed molecules was equivalent to an apparent molecular weight reduction of about 20,000 (e.g., 235,000 vs. 215,000 for PC12 cells). Thus, it appears possible that the high molecular weight neuronal components may be shed from the cell surface in forms that are slightly altered from those found in the membrane, although at present there is no evidence other than immunological crossreactivity to prove that the extracted and shed molecules are the same.

In order to determine whether neurons in primary culture also have cell surface proteins that are recognized by anti-PC12, we performed iodinations and immune precipitations on several types of primary cultures (Fig. 7). In the cerebellar cultures, in which $90 \%$ or more of the neurons are thought to be granule cell neurons (Currie and Dutton, 1980), anti-PC12 precipitated a major component of 215,000 daltons as well as other components with apparent molecular weights of 190,000, 150,000 , and 140,000. Similarly, in spinal cord cultures, a major component of about 215,000 daltons was seen. This 215,000-dalton spinal cord component had a slightly greater electrophoretic mobility than the cerebellar component, and the two could be distinguished when electrophoresed over longer distances (data not shown). In DRG cultures a major 225,000-dalton component was found, but its source was ambiguous, since anti-PC12 recognized both neurons and Schwann cells in these cultures. Clarification of this, using more homogeneous cultures, will be described below.

A summary of anti-PC12-reactive components from various types of cells is shown in Table IIA. Almost all of the cell types had a pattern of anti-PC12-precipitable molecules that could be grouped into four molecular weight classes. We wanted to determine if there were any correlations between these classes of molecules and the hypothetical classes of antigens proposed earlier to account for the immunofluorescent staining behavior of anti-PC12. To do this, we performed immune precipitations with the same set of absorbed anti-PC12 sera used for the immunofluorescence experiments. Some examples of these precipitations are shown in Figure 8.

Adult brain-absorbed anti-PC12 was unable to precipitate labeled components from any of the cell types examined. This was consistent with the immunofluorescence data except for the case of PC12 cells, which were the only cell type found to stain with brain-absorbed anti-PC12 (see Table I). Thus we were unable to identify any labeled components specific to PC12 cells (see hypothetical antigen class $d$ under "Further absorption of anti PC12"). Adrenal-absorbed anti-PC12, however, still precipitated labeled bands from many of the cell types, but the number of bands was reduced consistently. Table IIB shows that absorption of anti-PC12 with adrenal
T'ABLE II

Components precipitated by anti-PC12 and various types of absorbed anti-PC12 ${ }^{a}$

\begin{tabular}{lccccc}
\hline $\begin{array}{c}\text { A. Anti-PC12 } \\
\text { Cell Type }\end{array}$ & Band 1 & Band 2 & Band 3 & Band 4 & Band 5 \\
\hline PC12 & 235 & 190 & 170 & 140 & $-^{b}$ \\
B35 & 225 & - & 160 & 140 & - \\
CBL $^{c}$ & 215 & 190 & 150 & 140 & - \\
DRG-N & 225 & 190 & - & 140 & - \\
SCG-N & 225 & 190 & - & 140 & - \\
Schwann & 225 & 190 & - & 140 & - \\
Adrenals & - & 190 & - & 140 & 120 \\
CBL-G & - & 190 & - & 140 & - \\
\hline
\end{tabular}

B. Anti-PC12 absorbed with adrenals (or cerebellar glia)

\begin{tabular}{lccccc} 
Cell Type & Band 1 & Band 2 & Band 3 & Band 4 & Band 5 \\
\hline PC12 & 235 & $* d$ & 170 & $*$ & - \\
B35 & 225 & - & 160 & $*$ & - \\
CBL & 215 & $*$ & 150 & $*$ & - \\
DRG-N & 225 & $*$ & - & $*$ & - \\
SCG-N & 225 & $*$ & - & $*$ & - \\
Schwann & 225 & $*$ & - & $*$ & - \\
Adrenals & - & $*$ & - & $*$ & $*$ \\
CBL-G & - & $*$ & - & $*$ & -
\end{tabular}

C. Anti-PC12 absorbed with adrenals and Schwann cells, adrenals and B35 cells, or adrenals and cerebellar cultures with neurons. No bands were precipitated from any of the cell types by any of these three antisera.

D. Anti-PC12 absorbed with adult brain. No bands were precipitated from any of the cell types.

${ }^{a}$ Apparent molecular weights are given in thousands of daltons.

${ }^{b}-$, no component in this size range.

CBL, cerebellar culture with neurons; CBL-G, cerebellar glial culture without neurons; DRG-N, cultures of pure DRG neurons; SCG-N, cultures of pure SCG neurons; Schwann, sciatic nerve Schwann cells.

${ }^{d *}$, component no longer precipitated after adrenal absorption.

tissue removed its ability to precipitate the $190,000-$ and 140,000 -dalton components from all cell types (as well as a 120,000-dalton component from adrenal cells, themselves). In contrast, bands 1 and 3 , the components in the $215,000-$ to 235,000 -dalton and 150,000 - to 170,000 dalton ranges, were still precipitated by adrenal-absorbed anti-PC12. (In Fig. 8 the data concerning band 3 are more obvious for some cell types than for others. In the case of PC12 and B35 cells, for example, the longer autoradiographic exposures required to see this band are not shown.) Adrenal cells lack both band 1 and band 3, and therefore no components were precipitated from these cells by adrenal-absorbed anti-PC12. This was true of both adult and newborn adrenal cultures.

Cerebellar glial cultures devoid of neurons (see "Materials and Methods") were similar to adrenal cultures in that anti-PC12 precipitated only the 190,000 dalton band 2 and the 140,000-dalton band 4, and adrenalabsorbed anti-PC12 failed to precipitate any labeled components. The 190,000- and 140,000-dalton components must be present at relatively low density on the nonneuronal cells in our brain cultures since anti-PC12, even before absorption with adrenals, does not visibly stain any cells other than neurons in immunofluorescence experiments. Alternatively, antigenic determinants on these two molecules might be unavailable to the antibody until after detergent extraction, so that they are not 
recognized on intact glial cells but only in NP40 extracts. treated with anti-PC12 for 30 min and then were washed This latter alternative was ruled out in two ways. First, free of excess antibody. NP40 extracts then were made intact cerebellar glial cells surface labeled with ${ }^{125} \mathrm{I}$ were from these cells and treated with goat anti-rabbit im-
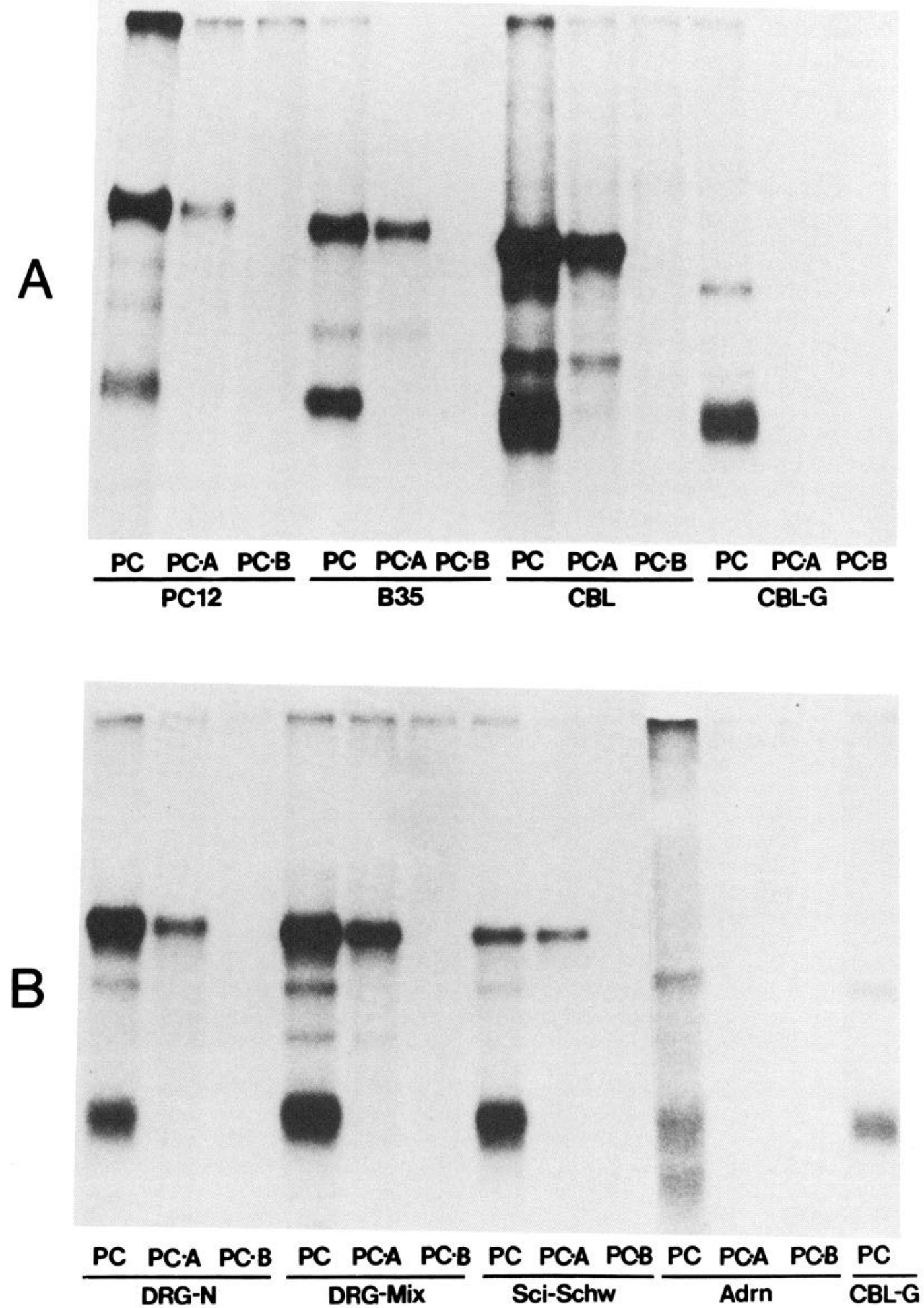

Figure $8 .{ }^{125}$ I-labeled membrane components precipitated by adrenal- and brain-absorbed anti-PC12. These autoradiographs were prepared from $5 \%$ polyacrylamide-SDS gels. The immune precipitates were prepared from NP40 extracts of the indicated cell types using rabbit anti-PC12 $(P C)$, adrenal-absorbed anti-PC12 $(P C-A)$, and brain-absorbed anti-PC12 $(P C-B)$. $A$, The cell types used were PC12 cells, B35 cells, cerebellar cultures $(C B L)$ and cerebellar glial cultures devoid of neurons $(C B L-G)$. $B$, The cell types used were DRG neurons (DRG-N), DRG cultures with both neurons and Schwann cells (DRG-Mix), sciatic nerve Schwann cells (Sci-Schw), adrenal medulla (Adrn), and cerebellar glial cultures without neurons $(C B L-G)$. 
munoglobulin and sufficient normal rabbit serum to produce immune precipitation. The immune precipitates obtained from the glial cells pretreated with anti-PC12 contained the same bands 2 and 4 seen in the precipitates obtained from extracts made prior to the addition of antiPC12. This shows that the 190,000- and 140,000-dalton components are exposed on the glial cell surface prior to cell lysis in NP40. Second, when anti-PC12 was absorbed with intact cells from neuron-free cerebellar cultures, it failed to precipitate bands 2 and 4 from all cell types tested, again showing that the 190,000 - and 140,000-dalton components are expressed on the glial cell surface. In contrast to the adrenal absorptions, in which one absorption essentially removed the ability of anti-PC12 to precipitate bands 2 and 4 , three absorptions with cerebellar glia were required to remove this reactivity. This result (1) strengthens the argument that cerebellar glia have a comparatively low level of the 190,000 - and 140,000-dalton components on their surface and (2) shows that three absorptions are sufficient to allow the detection of a level of antigen(s) that is too low to be seen by immunofluorescence.

Like adrenal-absorbed anti-PC12, the glia-absorbed anti-PC12 was able to precipitate bands 1 and 3 from cell types that had these components, and it stained neurons and Schwann cells in immunofluorescence experiments. These observations show that the 190,000- and 140,000dalton molecules are common to all of the cell types tested, including adrenal chromaffin cells and cerebellar glia, and thus could belong to the class of antigen or antigens designated as $a$ in our immunofluorescent staining/absorption tests.

More interestingly, molecules in the 215,000 to 235,000 dalton range (band 1) are clearly cell surface markers for neurons and Schwann cells and thus could represent antigens in class $b$. The results in Figure $8 B$ show unambiguously that, like the neurons shown in Figure $8 A$, purified populations of DRG neurons and sciatic nerve Schwann cells (see "Materials and Methods") each had a band 1 component recognized by anti-PC12. In each case this component had a molecular weight of about 225,000 , but on longer gels it was found that the Schwann cell component migrated slightly ahead of the DRG neuron component. Purified SCG neurons also had a 225,000 -dalton component that was indistinguishable from that of DRG neurons. Molecules in the 150,000 - to 170,000 -dalton range also were present on some types of neurons, but the details of the expression of these molecules on Schwann cells and DRG neurons are not yet clear. Purified DRG neurons and sciatic nerve Schwann cells appeared to have very little or none of this band 3 component, while mixed cultures of DRG neurons and DRG Schwann cells clearly expressed a 170,000-dalton molecule. This molecule could be present on DRG Schwann cells and absent on sciatic nerve Schwann cells, or alternatively, its expression on one of the cell types in the mixed DRG cultures might be induced by interaction with the other cell type. This problem remains to be resolved.

Finally, when adrenal-absorbed anti-PC12 was absorbed further with (1) sciatic nerve Schwann cells, (2) cerebellar cultures with neurons, or (3) B35 cells, it no longer precipitated labeled components from any of the preparations (not shown), even though each of these absorbed antisera was able to stain DRG and SCG neurons in immunofluorescence tests (see Table I). Thus we were unable to identify molecules specific for DRG and SCG neurons even though the immunofluorescence results suggest that such antigens exist (class $c$ ).

\section{Discussion}

Lee et al. (1977) showed that by absorbing a guinea pig anti-PC12 serum with rat liver, spleen, kidney, and thymus, they could prepare an antiserum that was directed specifically against components of brain, superior cervical ganglia, and adrenal gland. The specificity of their antiserum was determined by using tissue homogenates in absorption and microcomplement fixation assays, so that the identity of the cell types which actually bound antibody was not determined. Nevertheless, since PC12 cells share a number of properties with both sympathetic neurons and adrenal chromaffin cells, it seemed plausible that the absorbed anti-PC12 antibody recognized neurons and chromaffin cells in the tissues that were examined. Our findings indicate that this is indeed the case. We have shown that anti-PC12 antisera absorbed with several non-neuronal cell lines stain specifically the neurons in several types of primary tissue culture preparations. Neurons from rat cerebrum, cerebellum, spinal cord, and both dorsal root and superior cervical ganglia were identified by staining with tetanus toxin and were shown to co-stain with both rabbit and guinea pig anti-PC12. Astrocytes, oligodendrocytes, and fibroblasts, identified by staining with anti-GFAP, antiGC, and anti-fibronectin, respectively, were not stained by anti-PC12. Additionally, anti-PC12 was found to stain two other neural crest derivatives: Schwann cells, identified by the RAN-1 marker, and adrenal chromaffin cells, identified by antibodies against dopamine $\beta$-hydroxylase. Other neural crest derivatives were not tested.

Further absorption of anti-PC12 with several types of cells and tissues made it clear that the antiserum was not monospecific but recognized multiple components. For example, anti-PC12 absorbed with adrenal tissue no longer stained adrenal chromaffin cells but still labeled all types of neurons and also Schwann cells. This adrenalabsorbed anti-PC12 could be restricted further by absorptions of three types: (1) with Schwann cells, (2) with cerebellar cultures, and (3) with the B35 neuronal cell line. Each of these three absorbed sera stained only DRG and SCG neurons and PC12 cells. Anti-PC12 absorbed with 18-day embryonic brain also lost the ability to stain Schwann cells and CNS neurons and continued to stain DRG and SCG neurons and PC12 cells. In contrast, antiPC12 absorbed with 2-month-old rat brain recognized only PC12 cells.

These observations suggested that anti-PC12 recognized several cell surface components on PC12 cells. These components appear to be distributed on various cell types according to the following scheme. $(a)$ There is a component shared by PC12 cells, brain, chromaffin cells, and cultured cerebellar glial cells. Other neuronal cell types and Schwann cells may also express this antigen, but the absorptions necessary to determine this were 
not performed. ( $b$ ) There is a component missing from chromaffin cells and cerebellar glia that is shared by PC12 cells, CNS neurons, and Schwann cells. The absorptions needed to determine whether DRG and SCG neurons have this component were not done. (c) A more restricted component is shared by DRG neurons, SCG neurons, adult brain, and PC12 cells. (d) At least one component is unique to $\mathrm{PC} 12$ cells. We found no evidence for any adrenal-specific components recognized by our antisera.

The contrasting results obtained from absorptions with adult and embryonic rat brain suggest that the antigenic determinant (or determinants) unique to sympathetic and sensory neurons is not found in embryonic brain but is present in adult brain. Additional absorptions with brains of intermediate ages show that this antigen appears in the brain sometime during the 2nd postnatal week. Since the primary brain cultures that we routinely used in our study were prepared from embryonic or early postnatal rats, we were not able to identify the cellular population in the brain which carries the antigen. We attempted without success to use cultures prepared from older animals to identify brain cells stained by embryonic brain-absorbed anti-PC12. Cerebellar cultures prepared from 10-day postnatal animals were of good quality but showed no staining with the antiserum. Cultures of other parts of the brain prepared from animals in the 2nd postnatal week were of such poor quality as to be useless for immunofluorescent staining. It is interesting to note that a monoclonal antibody, 38/D7, has recently been described which distinguishes SCG, DRG, and other peripheral neurons in culture from several types of cultured central neurons (Vulliamy et al., 1981). It is not possible at this time to make any comparison of the antigens recognized by this monoclonal antibody and by our various absorbed anti-PC12 sera which recognize only peripheral neurons, but in light of our results it would be interesting to determine the effect of absorption with embryonic and adult rat brain on the reactivity of the monoclonal antibody.

We were unable to find any evidence for the involvement of tetanus toxin receptors (gangliosides GD1b and GT1) or glycosaminoglycans in anti-PC12 binding. However, immunoprecipitation experiments with NP40 extracts of ${ }^{125} \mathrm{I}$-labeled cells have allowed us to identify several cell surface glycoproteins that are recognized by anti-PC12. Some of these molecules appear to fit into the scheme of cell surface components $a$ to $d$ that we proposed in the foregoing paragraphs, although it must be emphasized that there is no direct evidence that these components are responsible for the observed immunofluorescent staining patterns. Proof of this hypothesis will require that we duplicate our immunofluorescence results using antisera prepared against the specific glycoprotein components. Nevertheless, components with apparent molecular weights of 190,000 and 140,000 were found on the surfaces of neurons, Schwann cells, adrenal cells, and even CNS glia. These two components could easily belong to antigenic class $a$ according to the proposed scheme. It seems likely that these two common components are identical to the 180,000- and 140,000-dalton glycoproteins identified by Lee et al. (1981) using their
anti-PC12 antisera. They found, as we have, that these two components are shared by PC12 cells, sympathetic neurons, brain, and adrenals. The inability of anti-PC12 to stain CNS glia can be most readily explained by a low density of these two components on glial cells. Adrenal chromaffin cells, on the other hand, are stained and therefore must have a higher antigen density. Absorption of anti-PC12 with adrenal tissue (or with cultured CNS glia) removed the ability of the antiserum to precipitate the 190,000- and 140,000-dalton components from all cell types tested. Hirn et al. (1981) have described a monoclonal antibody, BSP-2, which immunoprecipitates cell surface glycoproteins with molecular weights of 180,000 , 140,000 , and 120,000 from cultured cerebellar cells. In immunofluorescence experiments using cerebellar cultures, this antibody labels specifically only the neuronal cells. This apparent specificity for neurons can be understood if we make the assumption that the BSP-2-precipitable $180,000-$ and 140,000 -dalton glycoproteins are the same as our anti-PC12-precipitable 190,000- and 140,000dalton glycoproteins which are present on CNS glia but at a density too low to be detected by immunofluorescence. Thus, unlike the case of anti-PC12, we would predict that absorption of the BSP-2 antibody with CNS glia or with adrenal tissue would render it unable to stain neuronal cells.

In contrast to this prediction for the BSP-2 antibody, both adrenal-absorbed anti-PC12 and CNS glia-absorbed anti-PC12 not only continued to stain neurons but also continued to precipitate a higher molecular weight component from all types of neurons and from Schwann cells. Thus this component corresponds to antigenic class $b$ in our model. These molecules varied in apparent size from 215,000 to 235,000 daltons, depending on the specific cell in question. Each of the components found on normal neurons and Schwann cells could be distinguished on the basis of its electrophoretic mobility, with the exception of the SCG and DRG nerve components, both of which had apparent molecular weights of 225,000 (Table III). Similarly, the neuronal cell lines could be distinguished on the basis of the apparent size of the glycoproteins recognized by anti-PC12. In the case of three of the neuronal cell lines, it appeared that the respective 215 ,

TABLE III

Cell surface molecules in the 215,000 to 235,000 -dalton range recognized by anti-PC12

\begin{tabular}{lc}
\hline \multicolumn{1}{c}{ Cell Type } & Apparent Molecular Weight \\
\hline Cell lines & \\
PC12 & 235,000 \\
B35 & 225,000 \\
C1300 cl. N18 & 220,000 \\
$\beta$ HC & 215,000 \\
& \\
Primary cultures & \\
Cerebellar neurons & 215,000 \\
Spinal cord neurons & $<215,000$ \\
DRG neurons & 225,000 \\
SCG neurons & 225,000 \\
Schwann cells & $<225,000$ \\
Chromaffin cells & None \\
Cerebellar glia & None \\
\hline
\end{tabular}


000 - to 235,000-dalton molecules might be shed from the cell surface in slightly altered forms, as reflected by decreases in their apparent molecular weights.

The 235,000-dalton molecule found on $\mathrm{PC1} 2$ cells is likely to be identical to the 230,000-dalton NILE glycoprotein identified by McGuire et al. (1978) which apparently is immunoprecipitated by the anti-PC12 sera prepared by Lee et al. $(1977,1981)$. As is the case with the 235,000-dalton component recognized by our anti-PC12 serum, the NILE glycoprotein is immunologically distinct from fibronectin, a cell surface protein of comparable size (McGuire et al., 1978). Our finding that the high molecular weight glycoprotein on SCG neurons has an apparent size of 225,000 daltons is also in agreement with the data of Lee et al. (1981). Akeson and Hsu (1978) also have described a glycoprotein with an apparent molecular weight of greater than 200,000 which can be precipitated both from detergent extracts and from culture medium of N18 neuroblastoma cells by anti-N18 antibodies. It seems very likely that this glycoprotein is identical to the 220,000-dalton molecule precipitated from N18 cells by anti-PC12.

Molecules in the 150,000- to 170,000 -dalton range also were precipitated from some neuronal cell types by adrenal-absorbed anti-PC12. Due to our uncertainty concerning the presence or absence of such a molecule on DRG and SCG neurons and Schwann cells, we do not at present know whether to include it in class $b$ ) as a component shared by neurons and Schwann cells.

Further absorption of adrenal-absorbed anti-PC12 with Schwann cells, cerebellar cultures, or B35 cells abolished the ability of the antiserum to precipitate labeled components from any of the cell types. This supports the conclusion that Schwann cells and neurons share a common component but unfortunately does not allow us to identify the DRG-SCG-specific antigen, corresponding to class $c$ above, proposed on the basis of immunofluorescence. Similarly, component $d$, the PC12specific antigen, remains unidentified since adult brainabsorbed anti-PC12 failed to precipitate labeled bands from $\mathrm{PC} 12$ or any other cell type. It is possible that the class $c$ and class $d$ antigens are not labeled by the lactoperoxidase iodination technique. In this event, biosynthetic labeling with ${ }^{14} \mathrm{C}$-amino acids and sugars may enable us to identify these components.

Although it does not stain neurons immunofluorescently as intensely as tetanus toxin, anti-PC12 is an important reagent because it recognizes neuron-specific cell surface glycoproteins distinct from the gangliosides recognized by tetanus toxin. Thus the antibody can be used as an independent criterion for identifying and studying neuronal cells both in tissue culture and in histological preparations. Preliminary results indicate that anti-PC12 and adrenal-absorbed anti-PC12 stain nerve fibers in frozen sections prepared from embryonic rat brain. Moreover, anti-PC12 can be used as a probe to study the glycoproteins it recognizes. The most interesting of these are likely to be the family of 215,000 - to 235,000 -dalton glycoproteins found on Schwann cells and on the various neurons. Obviously, these glycoproteins are similar enough to cross-react with anti-PC12, and yet the observed differences in electrophoretic mobilities must reflect differences in structure, either at the polypeptide or polysaccharide level. Such differences may make it possible to prepare more specific antisera, perhaps monoclonal antibodies, which are capable of recognizing individual species of these glycoproteins and thus of distinguishing individual types of neurons.

\section{References}

Akeson, R., and W. Hsu (1978) Identification of a high molecular weight nervous system specific cell surface glycoprotein on murine neuroblastoma cells. Exp. Cell Res. 115: 367-377.

Amano, T., E. Richelson, and M. Nirenberg (1972) Neurotransmitter synthesis by neuroblastoma clones. Proc. Natl. Acad. Sci. U. S. A. 69: 258-263.

Arner, L., and W. Stallcup (1981) Two types of potassium channels in the PC12 cell line. Brain Res. 215: 419-426.

Bignami, A., L. Eng, D. Dahl, and C. Uyeda (1972) Localization of the glial fibrillary acidic protein in astrocytes by immunofluorescence. Brain Res. 43: 429-435.

Brandt, B., S. Hagiwara, Y. Kidokoro, and S. Miyazaki (1976) Action potentials in the rat chromaffin cell and effects of acetylcholine. J. Physiol. (Lond.) 263: 417-439.

Brockes, J., K. Fields, and M. Raff (1977) A surface antigenic marker for rat Schwann cells. Nature 266: 364-366.

Brockes, J., K. Fields, and M. Raff (1979) Studies on cultured rat Schwann cells. I. Establishment of purified populations from cultures of peripheral nerve. Brain Res. 165: 105-118.

Bulloch, K., W. Stallcup, and M. Cohn (1977) The derivation and characterization of neuronal cell lines from rat and mouse brain. Brain Res. 135: 25-36.

Currie, D., and G. Dutton (1980) ${ }^{3}$ H-GABA uptake as a marker for cell type in primary cultures of cerebellum and olfactory bulb. Brain Res. 199: 473-481.

Dichter, M., A. Tischler, and L. Greene (1977) Nerve growth factor-induced increase in electrical excitability and acetylcholine sensitivity of a rat pheochromocytoma cell line. Nature 268: 501-504.

Dimpfel, W., R. Huang, and E. Habermann (1977) Gangliosides in nervous tissue cultures and binding of ${ }^{125} \mathrm{I}$-labeled tetanus toxin, a neuronal marker. J. Neurochem. 29: 329-334.

Fields, K., J. Brockes, R. Mirsky, and L. Wendon (1978) Cell surface markers for distinguishing different types of rat dorsal root ganglion cells in culture. Cell 14: 43-51.

Goodman, R., and H. Herschman (1978) Nerve growth factor mediated induction of tyrosine hydroxylase in a clonal phenchromocytoma cell line. Proc. Natl. Acad. Sci. U. S. A. 75: 4587-4590.

Greene, L., and G. Rein (1977) Synthesis, storage, and release of acetylcholine by a noradrenergic pheochromocytoma cell line. Nature 268: 349-351.

Greene, L., and A. Tischler (1976) Establishment of a noradrenergic clonal line of rat adrenal pheochromocytoma cells which respond to nerve growth factor. Proc. Natl. Acad. Sci. U. S. A. 73: 2424-2428.

Hawrot, E., and P. Patterson (1979) Long-term culture of dissociated sympathetic neurons. Methods Enzymol. 58: 574584.

Hirn, M., M. Pierres, H. Deagostini-Bazin, M. Hirsch, and C. Goridis (1981) Monoclonal antibody against cell surface glycoprotein of neurons. Brain Res. 213: 433-439.

Hubbard, A., and Z. Cohn (1972) The enzymatic iodination of the red cell membrane. J. Cell Biol. 55: 390-405.

Kidokoro, Y., M. Anderson, and Y. Gruener (1980) Changes in synaptic potential during acetylcholine receptor accumulation and neurospecific interactions in Xenopus nerve-muscle cell culture. Dev. Biol. 78: 464-483.

Laemmli, U. (1970) Cleavage of structural proteins during the 
assembly of the head of bacteriophage T4. Nature 227: 680685.

Lee, V., M. Shelanski, and L. Greene (1977) Specific neural and adrenal medullary antigens detected by antisera to clonal PC12 pheochromocytoma cells. Proc. Natl. Acad. Sci. U. S. A. 74: 5021-5025.

Lee, V., M. Shelanski, and L. Greene (1980) Differential cytotoxic activities of antisera against nerve growth factor-treated and untreated clonal pheochromocytoma cells. Neuroscience 5: 1979-1987.

Lee, V., L. Greene, and M. Shelanski (1981) Identification of neural and adrenal medullary surface membrane glycoproteins recognized by antisera to cultured rat sympathetic neurons and PC12 pheochromocytoma cells. Neuroscience, 6: 2773-2786.

McGuire, J., L. Greene, and A. Furano (1978) NGF stimulates incorporation of fucose or glucosamine into an external glycoprotein in cultured rat PC12 pheochromocytoma cells. Cell 15: 357-365.

Mirsky, R., L. Wendon, P. Black, C. Stolkin, and D. Bray (1978) Tetanus toxin: A cell surface marker for neurons in culture. Brain Res. 148: 251-259.

Patrick, J., and W. Stallcup (1977a) Immunological distinction between acetylcholine receptor and the $\alpha$-bungarotoxin binding component on sympathetic neurons. Proc. Natl. Acad. Sci. U. S. A. 74: 4689-4692.

Patrick, J., and W. Stallcup (1977b) $\alpha$-Bungarotoxin binding and cholinergic receptor function on a rat sympathetic nerve line. J. Biol. Chem. 252: 8629-8633.

Raff, M., R. Mirsky, K. Fields, R. Lisak, S. Dorfman, D. Silberberg, N. Gregson, S. Liebowitz, and M. Kennedy (1978) Galactocerebroside: A specific cell surface antigen marker for oligodendrocytes in culture. Nature 274: 813-816.

Ransom, B., E. Neale, M. Henkart, P. Bullock, and P. Nelson (1977) The mouse spinal cord in cell culture. I. Morphology and intrinsic neuronal electrophysiological properties. J. Neurophysiol. 40: 1132-1150.

Ritchie, A. (1979) Catecholamine secretion in a rat pheochro- mocytona cell line: Two pathways for calcium entry. J. Physiol. (Lond.) 286: 541-561.

Schachner, M., G. Schoonmaker, and R. Hynes (1978) Cellular and subcellular localization of LETS protein in the nervous system. Brain Res. 158: 149-158.

Schubert, D. (1976) Proteins secreted by clonal cell lines. Exp. Cell Res. 102: 329-340.

Schubert, D., S. Heinemann, W. Carlisle, H. Tarikas, B. Kimes, J. Patrick, J. H. Steinbach, W. Culp, and B. Brandt (1974) Clonal cell lines from the rat central nervous system. Nature 249: 224-227.

Schubert, D., S. Heinemann, and Y. Kidokoro (1977) Cholinergic metabolism and synapse formation by a rat nerve cell line. Proc. Natl. Acad. Sci. U. S. A. 74: 2579-2583.

Schubert, D., M. LaCorbiere, C. Whitlock, and W. Stallcup (1978) Alterations in the surface properties of cells responsive to nerve growth factor. Nature 273: 718-723.

Stallcup, W. (1979) Sodium and calcium fluxes in a clonal nerve cell line. J. Physiol. (Lond.) 286: 525-540.

Stallcup, W. (1981) The NG2 antigen, a putative lineage marker: Immunofluorescent localization in primary cultures of rat brain. Dev. Biol. 83: 154-165.

Stallcup, W., and M. Cohn (1976) Correlation of surface antigens and cell types in cloned cell lines from the rat central nervous system. Exp. Cell Res. 98: 285-297.

Stallcup, W., and J. Patrick (1980) Substance P enhances cholinergic receptor desensitization in a clonal nerve cell line. Proc. Natl. Acad. Sci. U. S. A. 77: 634-638.

Vulliamy, T., S. Rattray, and R. Mirsky (1981) Cell-surface antigen distinguishes sensory and autonomic peripheral neurones from central neurones. Nature 291: 418-420.

Wilson, S., E. Baetge, and W. Stallcup (1981) Antisera specific for cell lines with mixed neuronal and glial properties. Dev. Biol. 83: 146-153.

Yaffe, D. (1968) Retention of differentiation potentialities during prolonged cultivation of myogenic cells. Proc. Natl. $\Lambda$ cad. Sci. U. S. A. 61: 477-683. 